\title{
EXPERIENCE WITH TYPHOID FEVER AT SHANTA BHAWAN
}

\author{
by \\ Jane Dorman* \\ \&
}

John Dickinson, B. M., B. Ch., M. R. C. P., ${ }^{* *}$

INTRODUCTION. From the text books, the student of tropical medicine might form : the impression that the dianosis of typhoid fever is a relatively simple matter; he receives a clear-cut description of the step-wise rising temperature in the first week, the sustained fever in the second and third weeks, never falling to normal, the clouded consciousness, the: constipation, the famous rose spets, relative bradycardia, splenomegaly and leucopenia. In practice there can be few of us who have not spent perplexed hours over obscure fever cases, wondering whether or not to use Chloramphenicol, and who have not regretied failing to use it earlier. Hence the despairing cry of a previous Shanta Bhawan physician: "All typhoid in Nepal is atypical."

Apart from the desise to come to grips with a common clinical problem in Nepal, this small study was stimulated by a paper by Wicks et al of the University College of Rhodesia, (1) who propounded, and supported by studying a large series, the theory that iyphoid in endemic areas gives a different clinical picture from the epidemic typhoid described in the text books and committed to the memory circuits of generations of doctors.

We set out therefore to see if the Rhodesia experience is paralleled in our practice at Shanta Bhawan. However, at the outset it is necessary to acknowledge severe limitatious in our study. The first is the size; in the attempt to present a personal series, children were excluded

"Medical Student, St. Mary's Hospital, London ** Physician, Shanta Bhawan Hospital 
and, in the period March 1971 to July 1972 for which records were readily available, only 3 cases were found. The second and more serious limitation is the criterion for a diagnosis of typhoid. Whereas the Rhodesian group used recovery of S. typhi and some post-morturit evidctee, our main criterion of necessity was response to Chloramphenicol therapy in a febrilo illness of compatible clinical features. For various reasons bacteriolozical studies were rarely performed and even more rarely positive. Almost certainly, therefore, our series contains a certain number of self-limiting viral or oiher fevers which gave the impression of responding to specific therapy.

As a study on which to base a theory, our series was clearly inadequate, but we believedt it may be of value to set our results beside those of the Rhodesinn group and consider similar ities and differences.

RESULTS: (a) Symploms. The patients' complaints are listed in Table [ and theint percentage frequency compared with that of the Rhodesian series. A marked difference is the fact that only $39 \%$ of the Africans gave a complaint of fever, whereas $100 \%$ of our patient did make this complaint. There may be a cultural explanation for this difference. On the ond hand, fever is a common complaint in Nepal, even among those with no objective pyrexia, andf the word is probably used by some to describe any form of malaise On the other hand, in Rhodesia, where malaria is common, it may be that people. reserve the term 'fever' for the shaking chills characteristic of this condition.

Our figures, small though the numbers are, confirm the frequency of abdominal pain $(39 \%)$; cough $(26 \%)$, headache $(29 \%)$, arthralgia $(19 \%)$, vomiting $(35 \%)$ and the fact that typhoid patients more commonly have diarrhoea $(39 \%)$ than constipation (23\%). Epistaxi 4$)$ frequently described in text books, was not seen.

(b.). Signs. Vague abdominal tenderness was found in $39 \%$ of cases Though only 2.case had : clinical-dehydration, the complaint of dysuria suggests that somedegree of fluid deficienot is :much more-common. When present, the withdrawa, lethargic "cloudy". state of mind frong which the disease derives its name (Greek : tuphos = cloud) was helpful. Splenomegal occurred in about half of our cases and, though non-specific, is probably more belpfulit diagnosis than in malarious regions such as Rhodesia.

We endeavoured to demonstrate relative bradycardia by tiking the means of the fir four temperatures and pulse readings after admission for each patient and plotting them on graph. Taking as a standard the experted rise of puls $\approx$ rate for each degree Fahrenbeit from; well-known text book (2), we found that our patients showad no significant tendency bradycardya, and in fact the readings were randomly scattered on either side of the expect values: This was true even when only patients with a short history were included, even thoug the tendency to be ibradycardi 1 is said to be more marked in the first week (3). O.lly two pati nt had : pulse rates of more than 20 beats below the expec'ed value. In the Rhodesian series; out of 140 patients with a history of one week or less, and 26 out of 103 patients with a long b.storys: had bradycarjia. 
- As in the Rhodesian serics, rose spots were nut seen. Since the series was completed, we bave seen a Western patient who developed a partially purpuric rash on the trunk and legs during an attach" of typhoid This did not resemble rose spots.

Two cases developed orchitis during the illness.

The pattern of fever was studied in our series though not in the Rhodesian one. An evening: fever similar to that of tuberculosis was preseni in 12 cases $(29 \%)$. In $10 \%$ the temperature fell to normal at some point during the day and in $49 \%$ there were marked falls to below 100 . F during the day In no case was the fever sustained at a high level throughout. the day.

3. Investigations: Table 3 shows that a leucopenia was by no means the rule, and, in fact, $23 \%$ had a white cell count over 10,000 .

From a survey of the Incal populati $n$, the Rhodesian group considered that Widal 0 or $\mathrm{H}$ antigen titres of $1 / 480$ ur over were diagnostic of typhoid, and that above this level there were unlikely to be false positives due to anamuestic reactions or infection with other Salmonellae. Such a study remains to be done in Nepal Table 4 snows the results of single widal tests in our study. The main conclusion that may be drawn is that false negative results are commoner in tbe first week of the illness, as might be expected. The value of rising titres was not studied.

4. Treatment. Chloramphenicol was used in all cases, and nearly all cases appeared to respond within a week. Table 5 shows the speed of response of 27 cases, and demonstrates the importance of continuing a therapeutic trial for at least a week. Corticosteroids were not used, largely because we were relying heavily upun defervescence as proof of success of the clinical trial and therefore hesitated to mask the fever with steroids. No cases of bone marrow depression were seen.

5. Age Incidence. The figures in Table 6 show that the disease was commonest in young adults' (Children were not included in the series.) There was no significant sex difference.

6. Seasonal Incidence. It will be seen from Table 7 that there was a general tendency for the disease to be commonest in the rainy seasons, June to August. However case; did occur throughout the year and in 1971, when the rains began in April, there was no increased incidence in the unusually wet months, April and May. On the other hand these pre-monsoon months, A pril and May, produced a relatively high incidence in 1972. It is not posible from these limiled numbers to decide if the disease is mainly spiead in the pre-monsoon period when drinking water is limited and stagnant water must be used, or whether it is disseminated by the rains. Probably both mechanisms operate.

COVCLUSIONS. We believe that our experience confirms the difficulty of applying lext book descriptions to typhoid in this endemic area The reason is presumably that patients have a degree of resistance, possibly acquired by previous exposure, that masks many of the 
classical features. The practitioner in Nepal should not hesitate to diagnose typhoid in the presence of tachycardia or leucocytosis, or in the absenee of splenomegaly. The fever pattern ia not typical and may indeed mimic that of tuberculosis or hidden abscess. The Widal test was never conclu ive and we have not found it very helpful,

The combination of fever for more than a few days, vague abdominal symptoms, cough and often headache and mental changes, in the absence of chest $x$-ray changes of pulmonary tuberculosis is nowadays usually sufficient to cause us to treat with $\mathrm{Chloramphenicol.}$

\section{References}

1. Wicks, Holmes and Davidson, Quart. J. Med. XL 159, 34!-54.

2. Adams and McGraith. Clinical Tropical Diseases 4th Ed. 1966.

3. Tidy Synopsis of Medicine 10th Ed. Bristol. 1954.

TABLE 1

SYMPTOMS.

\begin{tabular}{lcr} 
Symptom & Number of Cases & $\%$ \\
\cline { 2 - 3 } Fever & 31 & 100 \\
Abdominal Pain & 12 & 39 \\
Diarroea & 12 & 39 \\
Vomiting & 11 & 35 \\
Anorexia & 11 & 35 \\
Headache & 9 & 29 \\
Cough & 8 & 26 \\
Constipation & 7 & 23 \\
Arthraigia & 6 & 19 \\
Dysuria & 6 & 19 \\
Chest Pain & 5 & 16 \\
Weakness & 4 & 13 \\
Sore Throat & 3 & 10 \\
shivering & 3 & 10 \\
Dizziness & 3 & 10 \\
Haemoptysis & 3 & 10 \\
Abdominal distension & 1 & 3 \\
Dyspnoea & 1 & 3 \\
Dyspepsia & 1 & 3 \\
Melaena & 1 & 3 \\
Epistaxis & - & -
\end{tabular}

Rhodesian Series 
TABI.E 2

SIGNS

\begin{tabular}{lcccc} 
Sign & \multicolumn{1}{c}{ Number of Cases } & & Rhodesian Series \% \\
\cline { 2 - 3 } Pyrexia & 30 & & 97 & 98 \\
Splenomegaly & 14 & & 48 & 33 \\
Abdominal tenderness & 12 & 39 & 33 \\
Chest signs & 8 & 26 & 33 \\
Mental cbanges & 6 & 20 & - \\
Anaemia & 4 & 13 & 33 \\
Relative Bradycardia & 2 & 7 & - \\
Dehydration & 2 & 6 & 20 \\
Neck Stiffness & 1 & 3 & 0 \\
Rash & 0 & 0 &
\end{tabular}

TABLE 3

INITIAL WHITE CELL COUNT IN 30 CASES

W. C. C. / cu : mm

Less than 5000

$5000-10,000$

More than 10,000

\begin{tabular}{c} 
Number of Cases \\
\hline 9 \\
14 \\
7
\end{tabular}

Rhodesian Series \%

46

46

8

TABLE 4

WIDAL H OR O ANTIGEN TITRES, RELATED TO HISTORY

\begin{tabular}{|c|c|c|c|c|c|}
\hline Length of History & No. & & Not done & Negative & Less than $1 / 320$ \\
\hline $1-7$ days & 14 & & 1 & 2 & 5 \\
\hline $8-14$ days & 8 & & 3 & 0 & 1 \\
\hline $15+$ days & 9 & & 2 & 0 & 0 \\
\hline \multirow[t]{6}{*}{ Total } & 32 & & 6 & 2 & 6 \\
\hline & $1 / 320$ & or & More & & \\
\hline & 6 & & & & \\
\hline & 4 & & & & \\
\hline & $s$ & & & & \\
\hline & 15 & & & & \\
\hline
\end{tabular}


TABLE 5

NO. OF DAYS OF PYREXIA AFTER COMMENCEMENT OF CHILORAMPHENICO

\begin{tabular}{lrrrrrrrrrrr}
\hline No. of days & $\cdots$ & $0-1$ & 2 & 3 & 4 & 5 & 6 & 7 & 8 & 9 & 10 \\
\hline No. of cases & 4 & 4 & 4 & 4 & 5 & 4 & 4 & 2 & 0 & 0 \\
\hline
\end{tabular}

TABLE 6

AGE AND SEX INCIDENCE

\begin{tabular}{lccccccc} 
Age & $15-19$ & $20-24$ & $25-29$ & $30-34$ & $35-39$ & $40-44$ & $45-49$ \\
\hline Male & 0 & 4 & 7 & 2 & 0 & 0 & 0 \\
\hline Female & 3 & 5 & 6 & 0 & 1 & 1 & 1 \\
\hline Total & 3 & 9 & 13 & $\frac{2}{13}$ & 1 & 1 & 1 \\
\hline & & & $\frac{55-59}{0}$ & & & \\
& & & $\frac{1}{1}$ & & &.
\end{tabular}

TABLE 7

SEASONAL INCIDENCE

Month 1971

March

April

May

June

July

August

September

October

November

Deçmber

\begin{tabular}{c} 
No. of cases \\
\hline 1 \\
0 \\
1 \\
0 \\
4 \\
2 \\
0 \\
2 \\
1 \\
3
\end{tabular}

No. of ca

Month 1972

January

February

Marcb

April

May

June

July
0

0

3

4

3

2 